\title{
Rupturas e transformaçóes na vida de jovens acompanhados em um CAPS adulto
}

I ${ }^{1}$ Aline E. Milhomens, ${ }^{2}$ Denise Martin I

Resumo: O objetivo deste artigo é se aproximar das rupturas e transformaçôes ocasionadas na vida de jovens que passaram pela experiência de sofrimento psíquico acompanhados em um CAPS Adulto na cidade de São Paulo. Esta pesquisa foi realizada através de uma etnografia no acompanhamento de um grupo de jovens do serviço. Foram utilizadas técnicas de observação participante, registros em um caderno de campo e entrevistas individuais. Pôdese observar comprometimento da sociabilidade, afastamento das amizades, limitações com o uso das medicaçóes e dificuldade de conseguir um emprego formal. O consumo de álcool e outras drogas surgiu como questáo para o cuidado, uma vez que permeia aspectos importantes de sociabilização. Nota-se a concepçáo de sofrimento psíquico pautada na ideia de doença, reflexo de como o CAPS e demais serviços de saúde abordam a temática. O CAPS se mostrou um espaço de acolhimento e confiança, especialmente nos momentos de crise, porém traz a discussão sobre quais estratégias utiliza para compor tal cuidado a essa população específica e do quão alinhadas estão com as políticas de saúde mental.

> Palavras-chave: jovem adulto; sofrimento psíquico; participação social; serviços de saúde mental.

\author{
1 Universidade Federal de \\ São Paulo, Departamento \\ de Medicina Preventiva. São \\ Paulo-SP, Brasil (lineernandes@ \\ gmail.com). \\ ${ }^{2}$ Universidade Federal de \\ São Paulo, Departamento \\ de Medicina Preventiva. São \\ Paulo-SP, Brasil (demartin.c@ \\ gmail.com).
}


A internação por questóes de saúde mental e o fechamento de um diagnóstico psiquiátrico carregam um peso histórico na sociedade que é sentido pelas pessoas e familiares que participam deste processo de adoecimento. As noçóes de periculosidade, alienação e inimputabilidade que fundamentaram e deram sustentação por muitos anos ao modelo psiquiátrico tradicional (AMARANTE; RANGEL, 2009) deixaram marcas na cultura brasileira que só recentemente começaram a ser mudadas.

A definição dos Centros de Atenção Psicossocial ${ }^{1}$ (CAPS) como porta de entrada na rede assistencial à saúde mental pela portaria GM 224/92 (BRASIL, 1992); sua composição na rede de serviços substitutivos aos hospitais psiquiátricos na Política de Saúde Mental do Sistema Único de Saúde (BRASIL, 2005); a criação da Lei 10.216, conhecida como a Lei da Reforma Psiquiátrica (BRASIL, 2001); e, por fim, a criação da Rede de Atençáo Psicossocial (BRASIL, 2011), foram alguns dos resultados das diversas lutas de profissionais da saúde, usuários e familiares iniciadas nos anos 1970 e que abriram caminho para iniciativas de mudanças no conjunto assistencial, jurídico e cultural, contribuindo para o processo de tranformação dos conceitos relacionados à loucura e a sua forma de cuidado.

Os CAPS passaram a ser os serviços de referência e tratamento para pessoas em sofrimento psíquico severo ou persistente que justificasse sua permanência num "dispositivo de cuidado intensivo, comunitário, personalizado e promotor de vida” (BRASIL, 2004). Com o objetivo de se adaptar aos diversos perfis e faixas etárias de acordo com a necessidade de tratamento, foram criadas três modalidades de CAPS: adulto; álcool e drogas; e infantil ou infantojuvenil, regulamentados somente em 2002 com a Portaria n. 336 (BRASIL, 2002). Anteriormente a isto, os jovens e adolescentes que necessitassem de algum tipo de acompanhamento ficavam à mercê de instituições filantrópicas, hospitais psiquiátricos e até mesmo na Fundação para o Bem-Estar do Menor (Febem), onde se confundia sofrimento psíquico com delinquência (TAÑO; MATSUKURA, 2015).

Tendo como foco essa populaçáo jovem no contexto da saúde mental presente, este artigo tem como objetivo se aproximar das rupturas e transformaçôes ocasionadas na vida de jovens que passaram pela experiência de sofrimento psíquico que realizam acompanhamento em um CAPS Adulto, assim como da 
vivência da fase da juventude diante deste processo. Para tal fim, acompanhou-se

um grupo chamado "Grupo Jovens" em um CAPS Adulto localizado na regiáo metropolitana de São Paulo.

Observa-se na bibliografia nacional que pouco se tem produzido academicamente sobre a temática da juventude e sofrimento psíquico grave em um CAPS Adulto (BLIKSTEIN, 2012; COSTA, 2006; CUNHA; BOARINI, 2011; TAÑO; MATSUKURA, 2015). Alguns dos trabalhos existentes fazem referência ao sofrimento psíquico na infância e adolescência, sem abordar a questão da juventude como uma fase diversa, além de serem voltados para os acompanhamentos realizados nos CAPS Infantis. Há uma produção relacionada à juventude, porém atrelada ao uso de álcool e outras drogas e não exclusivamente ao sofrimento psíquico (ADADE; MONTEIRO, 2014; GRANJA et al., 2015; SOARES et al., 2017; SOARES et al., 2009). Dessa forma, é importante olhar para essa juventude brasileira em específico, que não está, em sua maioria, fechada em hospitais psiquiátricos, mas circulando de forma particular, pensando seu futuro e construindo itinerários próprios dentro dos limiares referentes ao sofrimento psíquico.

\section{Juventude e saúde mental}

Múltiplos fatores e marcos sociais condicionam as diversas maneiras de ser jovem, uma vez que a condiçâo histórico-cultural da juventude não é ofertada de forma igual para todos (MARGULIS; URRESTI, 1996). Para os jovens que cedo experienciam o sofrimento psíquico, a vivência dessa fase vem atravessada por fatores como: tratamentos; internaçóes; uso de psicofármacos e seus efeitos colaterais; afastamento das atividades laborativas e educativas; e perda parcial da autonomia, que contribuem para que estes jovens sigam de um modo singular e provavelmente distante das expectativas sociais desta faixa etária.

Para discorrer sobre essa população específica e seus períodos de crise, partiremos da ideia de crise psíquica ou sofrimento psíquico como uma experiência subjetiva e única vivida de forma intensa e solitária. Intensa por ser contínua e de longa duração, alterando a rotina do sujeito no que se refere a sono, alimentação e autocuidado; e solitária, por ser uma experiência de difícil partilha. Dell'Acqua e Mezzina (1991) caracterizam a crise como uma intrincada situação existencial, que exige complexos instrumentos e recursos para lidar com a mesma. 
Blikstein (2012), em estudo sobre internações de crianças e adolescentes em Hospital Público Psiquiátrico da cidade de São Paulo, entre 2005 e 2009, aponta que a internação é um recurso ainda fortemente utilizado como única intervenção para crianças e adolescentes. Segundo a autora, a prática de internação ocorre, principalmente, através de ordens judiciais e de encaminhamentos de serviços de saúde, que, em alguns casos, não possuem um CAPS Infantil de referência em seu território. Dos 354 prontuários estudados, 88\% eram de adolescentes de 12 a 18 anos, abrindo grandes possibilidades para um início de uma carreira manicomial entre essa população.

Nos períodos da vivência da crise psíquica, evitar a internação psiquiátrica é evitar um desenrolar estigmatizante que pode se perpetuar por todo seu processo de desenvolvimento. A breviedade da intervenção, o tipo de intervenção e a duração do tratamento são fatores importantes a se atentar durante tal processo (LOUZÃ, 2000), assim como os fatores sociais; ambientais; etários; de gênero; familiares; de etnia, que também influenciarão o modo com que essa crise se desenvolverá e a sua repercussão na vida deste jovem. A utilização de uma ampla rede de recursos e instrumentos, como serviços territoriais do âmbito da saúde, da assistência social, moradia, educação e cultura, são fundamentais na construção desse cuidado e para a produção de uma vida desinstitucionalizada e não estigmatizada pela loucura em seu aspecto negativo.

\section{De que juventude estamos falando?}

O termo juventude é polissêmico, por tratar de um conjunto de diversos elementos dos campos das ciências biológicas, sociais e da psicologia. Neste trabalho, o conceito se pautará no campo das Ciências Sociais de juventude como construção cultural e histórica cujas singularidades estão de acordo com os recortes biológicos, de gênero, de etnia, socioeconômicos e culturais (PAIS, 1990). A partir disto, o conceito de juventude não é apreendido de forma uniforme ou por uma categorização etária por delimitar processos singulares que não necessariamente estáo determinados a um tempo cronológico. $\mathrm{O}$ uso do termo juventudes no plural (MARGULIS; URRESTI, 1996; PAIS, 1990) tem sido utilizado no intuito de reforçar uma não homogeneidade e trazer aos olhos a diversidade com que esta população se apresenta, assim como suas diversas demandas para a costrução de políticas públicas e práticas de cuidado. 
No contexto dos serviços e políticas de saúde mental do SUS, a especificação do conceito de juventude, bem como seu perfil populacional, é pouco abordada, sendo usada normalmente como sinônimo de adolescência (BRASIL, 2005). Em sua maioria, juventude é definida e restrita aos critérios etários como observado nas modalidades de CAPS cuja nomenclatura já especifica o público-alvo a ser atendido: CAPS Adulto, para pessoas a partir de 18 anos; CAPS Infantil ou Infantojuvenil, para crianças e adolescentes até 18 anos (BRASIL, 2004).

Não especificar essa população nos documentos de saúde mental abre a possibilidade para uma menor visibilidade desta, principalmente nos CAPS Adultos, uma vez que a população jovem não costuma ser sua maioria.

\section{Percurso metodológico}

Os jovens participantes desta pesquisa residem em Cidade Tiradentes, bairro localizado na periferia da regiáo leste de São Paulo, a 35 quilômetros do marco zero da cidade. Classificado como de alta vulnerabilidade social no Índice Paulista de Vulnerabilidade Social (2011), o bairro apresenta cerca de 160.000 habitantes em moradias formais (conjuntos habitacionais) e $60.000 \mathrm{em}$ informais (favelas e loteamentos habitacionais clandestinos e irregulares). A renda média do chefe de família varia de 500 a 1.200 reais na moradia formal e de 200 a 500 reais na informal. Considerando o salário mínimo no ano de 2014 em 724 reais, a renda da população local se mostra baixa para uma cidade grande como Sáo Paulo (SÃO PAULO, 2014).

Segundo o IBGE (2000), Cidade Tiradentes é, juntamente com Guaianases, o bairro com maior número de homens negros, e o segundo com a maioria de mulheres negras. A taxa de analfabetismo é de 5,78\%, sendo maior que a do município de São Paulo, que fica em 4,88\% (IBGE, 2000).

Optou-se teoricamente para tratar este tema de pesquisa pela disciplina da Antropologia Urbana, por ter como cenário o contexto da grande metrópole caracterizada pela composição heterogênea de locais, pessoas, grupos, classes sociais (MAGNANI, 2003). A etnografia foi a estratégia de pesquisa através de um olhar de perto e de dentro (MAGNANI, 2002), a partir de arranjos dos atores sociais sobre o uso da cidade nas suas mais diversas esferas. Utilizou-se, também, da observação participante, do diário de campo e entrevistas individuais em profundidade com integrantes e ex-integrantes do grupo. 
A pesquisa de campo foi realizada no acompanhamento deste grupo pelas saídas pela cidade de São Paulo, no CAPS e na circulação pelo próprio bairro Cidade Tiradentes. Lugares públicos como privados, em trajetos a pé, de metrô, ônibus e trem, casas de integrantes, parques, shoppings, cinemas, Fábrica de Cultura, ${ }^{2}$ Teatro Municipal, museus, entre outros locais, compuseram alguns dos roteiros realizados em campo. Já dentro do CAPS, os cenários também eram diversos, como: a sala de grupo; o refeitório/cozinha; a sala de convivência; e o jardim. Dessa forma, a proposta do grupo não pretendia apenas circular pela cidade, mas pensar os usos possíveis desses espaços. O parque como um lugar de possibilidade para um piquenique, de jogar uma bola, estender uma canga, fazer uma caminhada, bater um papo, descansar. Atividades e lugares que podem parecer comuns, principalmente no que diz respeito ao lazer, porém, para a grande parte desses jovens, tanto pela condição socioeconômica, pela localização do bairro afastado do centro da cidade, quanto pela questão do sofrimento psíquico, eram experiências novas ou de grande dificuldade por tudo que elas demandavam: escolhas, exposiçáo de si, ida a lugares desconhecidos e longos deslocamentos que, em sua maioria, não levavam menos de uma hora.

As entrevistas realizadas foram semiestruturadas, direcionadas por um roteiro de questôes previamente elaborado, o qual permitiu uma organização flexível e a ampliação dos questionamentos à medida que as informações iam sendo fornecidas pelos entrevistados. Todas as entrevistas foram gravadas e transcritas pela própria pesquisadora após a leitura e assinatura do Termo de Consentimento Livre e Esclarecido. ${ }^{3}$

O convite para participar das entrevistas não foi feito de forma geral para o grupo, pois foi considerado que alguns integrantes náo estavam aptos naquele momento a tomar parte por estarem em um período de crise, não se enquadrando nos critérios éticos da pesquisa. Dessa forma, seis jovens participaram das entrevistas.

As entrevistas foram realizadas em duas etapas: na primeira, o objetivo era obter um panorama da vida dos entrevistados, como moradia, família, estudos, religiâo, percepção de si como jovem ou adulto, primeira crise e início de tratamento e acompanhamento em serviços de saúde mental desde a atenção básica até a especializada. $\mathrm{Na}$ segunda, foram feitas questôes relacionadas ao lazer, tempo livre, cotidiano e uso de redes sociais, sem abordar diretamente questôes relacionadas ao tratamento ou à experiência do sofrimento psíquico. 
$\mathrm{Na}$ primeira etapa, seis pessoas foram entrevistadas, sendo uma mulher e o restante homens entre 20 e 28 anos. Desses seis, um se recusou a participar da segunda alegando falta de tempo. Como perfil dos entrevistados, destacamos: todos residiam em Cidade Tiradentes, em moradias formais, sendo dois em casa e quatro em CDHU (Companhia de Desenvolvimento Habitacional e Urbano); todos concluíram o segundo grau; moravam com os pais; solteiros; sem filhos; três não trabalhavam, mas referiram estar à procura; dos que trabalhavam, a atividade era de cunho informal, como seguranças, auxiliar de pedreiro, vendas.

O local da realizaçáo da entrevista ficava a critério do entrevistado, podendo ser no CAPS, em sua residência ou em um local público, como praças, centros culturais etc. Apenas quatro, das onze entrevistas, foram realizadas fora do CAPS, sendo três destas nas residências e uma numa praça do próprio bairro de Cidade Tiradentes.

A análise dos dados ocorreu após a leitura exaustiva das transcriçóes das entrevistas e do diário de campo. Os dados considerados pertinentes a este recorte serão apresentados a seguir.

\section{Vivência do sofrimento psíquico, mudanças e implicaçóes no cotidiano}

Uma das primeiras formas de manifestação do sofrimento psíquico relatada pelos jovens referiu-se ao isolamento social e à mudança de humor expressa, em sua maioria, em comportamentos hostis com familiares e pessoas mais próximas de seus cotidianos:

Eu agredia meus pais... quase todo o dia era discussão em casa... era um inferno aqui... quase todo dia era discussão porque eu não trabalhava, eu não fazia curso, eu não saia de casa. [...] O prédio chegou a denunciar até porque era briga constante ( $\mathrm{R}$, homem, 20 anos).

Segundo eles, os familiares foram os primeiros a perceber tais mudanças e a incentivá-los ou forçá-los a buscar algum tipo de ajuda. Ajuda religiosa, médica e policial, nos casos de maior violência, apareceram como as mais frequentes nesse processo, até a chegada nos serviços de saúde mental que deram alguns tipos de respostas sobre o que esses jovens vinham vivenciando.

Observou-se através das entrevistas que os serviços de saúde mental em que esses jovens passaram ou em que seguem acompanhamento direcionavam o cuidado a partir da psiquiatria tradicional pautados na ideia de doença e 
diagnósticos fechados. Muitas de suas falas vinham permeadas de diagnósticos e do uso da palavra "doença" para descrição de seus estados. Em uma pesquisa sobre as necessidades de adolescentes em sofrimento psíquico, Mangia et al. (2003) constataram que, com frequência, os adolescentes recebem diagnósticos psiquiátricos e medicação a partir de uma única observação, e que em algumas situaçôes são submetidos à internação psiquiátrica desnecessária e estigmatizante, não acompanhada de medidas que assegurassem a continuidade do cuidado.

A ideia de sofrimento psíquico como doença é respaldada pelo CID-10 (Código Internacional de Doenças), o que possibilita o uso do diagnóstico médico para diversos trâmites burocráticos e acesso a direitos como: licença médica, solicitação de benefícios, carta de alta, encaminhamentos, entre outros. Ao mesmo tempo que o diagnóstico possibilita o acesso a benefícios e direitos sociais, estigmatiza o sujeito diante do aspecto negativo de doença, atrelado ao imaginário social da loucura. Dessa forma, a identidade construída no percurso de vida vai sendo elaborada e enraizada por aspectos que náo se sabe ao certo o quanto propulsores ou limitadores serão para a vida destes jovens.

Quando questionados sobre a compreensão que tinham sobre o termo loucura, percebe-se que, anteriormente a tais vivências, já havia uma concepção negativa. É interessante observar que em alguns casos não se tinha a concepção por doença até a chegada ao CAPS:

Aí foi aonde que eu fiquei ruim né,num tava conhecendo ninguém, tava vendo coisa e eu já tinha esse negócio de escutar vozes, mas pra mim era um negócio normal (F, homem, 26 anos).

A apropriação da sua experiência em relação à loucura com tranquilidade e propriedade de si demonstrou ser algo muito particular do processo de cada um, que pode ecoar ou não com o tempo. Quando ocorre, esses jovens acabam demonstrando uma melhor forma de lidar com as situaçôes sociais de "zoaçôes" e brincadeiras relacionadas a esta experiência.

Os outros me chamavam de Elias Maluco. Hoje em dia os outros chama ainda, eu levo na brincadeira, eu não me sinto ofendido. Quando eu tava ruim, eu me sentia ofendido, entendeu? Eu levo numa boa, entendeu (F, homem, 26 anos).

A partir de uma mudança de postura frente a si e aos próximos, ganha expressão um amadurecimento que permite, dentro dos limites e potencialidades de cada indivíduo, a (re)construção de novos laços a partir da nova configuração de sujeito. Essa reconfiguração perpassa os que estiveram e estão em contato com 
esses jovens, produzindo novos referenciais sobre a loucura e a possibilidade de sua existência na comunidade.

Tipo assim, eu tô me adaptando porque muita gente já sabe do meu probrema né, então muita gente não bota muita pressão, já sabe como é, que eu não tenho mais a agilidade de antes. [...] Antigamente quando as pessoa náo sabia do meu probrema, elas falava muito sobre isso né, porque eu ficava tremendo, entendeu (F, 26 anos, homem).

Em alguns dos entrevistados, principalmente os que estavam há mais de dois anos em acompanhamento, observou-se que, com a experiência das crises, vão adquirindo estratégias e ampliando as formas de lidar e de se perceber em relação ao próximo de modo a evitar situaçóes que possam ser constrangedoras para si e para os outros. Um dos entrevistados diz que pede para que seus pais o avisem quando ele não estiver bem. Outra integrante diz que quando percebe olhares estranhos para ela, cogita a possibilidade ser somente uma impressão errada, "coisa da minha cabe d" (D, mulher, 20 anos).

A capacidade de sociabilizar e os grandes grupos de amizades comuns aos jovens que não apresentam questôes de saúde mental ${ }^{4}$ foram dois aspectos observados durante o trabalho de campo com os jovens integrantes do grupo. A partilha de um mesmo gosto referente a uma especificidade que configura aspectos partilháveis e construtores de suas identidades não era muito presente. Apenas um dos jovens fazia frequente referência aos seus amigos do funk como um espaço identitário. Majoritariamente, o grupo a que esses jovens circulavam era o do CAPS, sem expressar nas entrevistas e durante o trabalho de campo outros grupos de que participassem. Nota-se que após a primeira crise psíquica, esses jovens se veem afastados das antigas amizades, apresentando importante isolamento social e perda destes pontos de partilha.

A ausência ou limitação referente às amizades apresentou-se nas entrevistas a partir de dois aspectos: o primeiro como resultado de uma mudança do próprio comportamento diante dos colegas, como uma dificuldade de interação, timidez, por exemplo; e um segundo aspecto, a partir da acusação aos colegas que se afastaram quando mais precisaram, fazendo referência ao período em que estavam em crise.

Ah mudei assim, que agora eu tomo remédio, às vezes, assim pra amizade eu fico mais na minha. As pessoas estão conversando e eu não tenho, parece assim que eu não tenho assunto com as pessoas, sabe? [...] Era aquela flor, amiga pra lá, amiga pra cá. Aí, quando quando que eu caí numa cama todo mundo desapareceu.[...] (D, mulher, 20 anos). 
A circulação pelo bairro após internação ou diminuição da crise vinha acompanhada da vergonha ante as pessoas próximas e da dificuldade de lidar com esses encontros e exposições perante olhares e perguntas que causam incômodo. Conseguir sair de casa sozinho, encontrar com vizinhos, comprimentá-los e andar até o ponto de ônibus eram enfrentamentos sociais do cotidiano importantes ao processo de sociabilização e, muitas vezes, difíceis de serem recuperados após a vivência de uma crise. A vergonha de si, dependendo da experiência que se teve, pode adquirir tal dimensão a ponto, como em um dos casos, de a pessoa não querer mais retornar à antiga residência, como refere um dos entrevistados:

\footnotetext{
Aí depois eu não voltei mais pra casa, fiquei meio traumatizado, com vergonha também na época. Tudo essas coisas da crise, de início você não sabe né, então fica: - Olha, o cara é doido... [...] (vergonha) das coisas que eu fiz né. [...] mesmo se eu pudesse, eu não voltaria a morar lá, sei lá, por vergonha, essas coisas... (M, homem, 28 anos).
}

Ao se abordar o tempo livre e o uso deste no dia a dia, a grande maioria referia ficar em casa, assistindo televisão, auxiliando nas tarefas domésticas e cuidando dos irmãos mais novos. Quando questionados sobre saídas, muitos diziam de idas à igreja, mercados e festas de familiares. Pouco se falava sobre baladas, prática de esportes, encontro com os amigos. Tais falas podem ser interpretadas pelo prisma de jovens "mais caseiros" ou "sussegados", com comportamentos que também estáo presentes em outros jovens do mesmo contexto sóciocultural e econômico, sem necessariamente estarem atrelados às questôes relacionadas ao sofrimento psíquico.

A inserção ao mercado de trabalho por "bicos" ou em negócios da família se apresentou como uma nova forma de reestruturar o cotidiano, após o início do acompanhamento. Tais modalidades de trabalho permitem maior flexibilidade de horário e podem ser realizadas nos dias em que a pessoa se sente apta para tal atividade, sem a rigidez e a baixa tolerância de um emprego formal. Nenhum dos jovens, no período das entrevistas, possuía emprego formal. Cinco deles haviam trabalhado com carteira assinada antes da primeira crise e somente um retomou este tipo de emprego após a crise, enquanto os outros, apesar das tentativas, não conseguiram, exercendo uma atividade laborativa sob outros moldes. Tal relação com o emprego informal pode estar atrelada às questôes de saúde mental, como citado anteriormente, mas também reflete um movimento da economia nacional de aumento na inserção do mercado de trabalho informal de jovens entre 15 e 29 anos, divulgado pela Pesquisa Nacional de Amostra por Domicílios (BRASIL, 2013). 


\section{Acompanhamento no CAPS}

A chegada ao CAPS, em sua maioria, deu-se após vários percursos anteriormente percorridos, como hospitais gerais, pronto-atendimentos e Unidades Básicas de Saúde. Grande parte dos integrantes do grupo foram levados ao CAPS acompanhados, principalmente, por suas mães. Entre os entrevistados, nenhum buscou ajuda sozinho, relatando estar assustado com a situação e medo de ser diagnosticado como louco.

Após a passagem no acolhimento ${ }^{5}$ no CAPS, o acompanhamento se inicia com a construção de um projeto terapêutico singular ${ }^{6}$ e com o agendamento da consulta com o/a psiquiatra, que provavelmente iniciará um tratamento medicamentoso como parte do tratamento ofertado. Atualmente, na rede de serviços de saúde mental do SUS, o uso de psicofármaco ${ }^{7}$ trabalha junto com a abordagem psicossocial e exige um acompanhamento cuidadoso pelos efeitos colaterais e adversos que estes podem causar (FIOCRUZ, 2006; XAVIER et al., 2014).

Em algumas situaçóes relatadas pelos entrevistados e vivenciadas no grupo, a medicação demonstrou atuar como um empecilho, principalmente nos primeiros meses de tratamento em que o corpo não está habituado às novas substâncias. A dificuldade de locomoção, de fala, de atenção e o sono excessivo chegavam a impossibilitar uma participação mais potente nos espaços sociais, como mostra a seguinte fala:

Eu fiquei um tempo com a língua presa, eu não me expressava muito bem, eu falava meio enrolado, o remédio dava muito sono, não conseguia acordar cedo e quando eu acordava, acordava meio dopado por causa das injeçóes que eu tomava [...] aí eu andava meio torto ( $\mathrm{R}$, homem, 20 anos).

Foi possível notar que no passar do tempo, com a medicação em uso, há um reconhecimento por parte dos jovens entrevistados referente à diminuição dos efeitos colaterais e à melhora no estado psíquico:

[...] as pessoas via que eu tava dopado, que eu não tava como eu era antes. Isso foi ruim pra mim, mas agora tá tudo bem... tô melhor (R, homem, 20 anos).

Um aspecto importante que surgiu referente à medicação foi relacionado à não clareza e finalidade da mesma. Grande parte dos entrevistados soube informar nomes e quantidades do medicamento em uso, porém, no que se referia à finalidade, ficou notável a ausência de esclarecimentos, principalmente quando se tratava de um antipsicótico. Esse não saber pode estar relacionado a um não 
esclarecimento por parte do médico ao prescrever; a uma recusa por parte do sujeito de não querer dizer a finalidade de tais medicamentos, uma vez que tratam de sintomas presentes que, de certa forma, "atestarão" a loucura; ou a uma confiança e crença no médico em relação à prescrição, de modo a não questionála. Por outro lado, mesmo sem o conhecimento técnico da finalidade, observouse uma apropriação da medicação através dos ganhos e perdas que esta acarretava em suas vidas, uma vez que muitos se sentiam aptos a uma autoadministração nos moldes considerados, por eles mesmos, adequados para o momento e contexto em que se encontravam, independente da prescrição e orientação, como exposto na fala abaixo:

Aí os moleques tava indo fumando uma maconha lá, aí eu ia... ficava olhando: - Será que eu posso? Será que não posso? - aí parei de tomar o remédio pra não prejudicar tipo, pensei assim: - Se eu para de tomar o remédio, acho que eu vou poder beber e vou poder usar droga. [...] Sem (a medicação) fico agitado, fico agitado, ando de um lado pro outro, arrumo a casa, arrumo tudo [risos] e tipo, já o coração, sei lá, meio que acelera. Eu sei lidar com isso, entendeu? Pra ficar mais tranqüilo fumo um cigarro, fumo até mais cigarro quando acelera o coração, mas isso tipo, se eu ficar uns, por exemplo: ficar hoje, hoje é quinta, se eu ficar até quarta sem tomar eu fico tranqüilo, mas como a médica falou, a medicação fica no organismo, tem uns dias e tal, mas se eu passar de uma semana sem tomar, vixi, sei lá, eu não sei se é isso ou é psicológico, pode dá uma insegurança, você já fica meio com receio, aí já fica pilhado... deve ser isso também ( $\mathrm{J}$, homem, 24 anos).

A interrupção da medicação para uso de álcool e outras drogas se revela como uma questáo para o tratamento. $\mathrm{O}$ risco de agravamento ou do desencadeamento de uma crise por interrupção abrupta da medicação é de três a cinco vezes maior quando comparado com uma pessoa que faz o uso contínuo (ROBINSON et al. apud BECHELLI, 2003). Há um conflito que estes jovens vivenciam ao ir a uma festa: não poder ingerir bebida alcoólica ou ter que justificar aos colegas o porquê de não estar bebendo são inconveniências que poucos aceitam ou lidam de forma positiva. Muitos optam por se afastarem dos colegas e dos espaços de lazer convidativos ao uso de bebidas e outras drogas, como forma de cuidado e de focar no tratamento. Esse tema era constantemente trazido por eles no grupo, e era de fundamental importância compreender o seu uso e o que estavam buscando, uma vez que o uso da medicação é muito particular e relacionado à própria experiência sobre benefícios e perdas que pode causar.

Entre as diretrizes dos CAPS está a promoção de autonomia, porém, pôdese notar durante a pesquisa que quando um desses jovens fazia uma escolha em 
relação ao seu acompanhamento, como interromper o uso da medicação, para fazer uso de drogas, ou para conseguir levantar cedo para estudar, tal atitude era vista pelo serviço como contrária ao tratamento. Como se o exercício da autonomia só coubesse quando exercida em concordância com a disciplina oferecida pelo serviço. Optar por não mais fazer uso da medicação é tratado como irresponsabilidade ou "piora do quadro", "pois cada um de seus atos se encontra constantemente circunscrito e definido pela doença” (BASAGLIA, 2010, p. 117).

Em relação aos demais grupos do CAPS, um dos entrevistados fez uma crítica quanto à infantilização das atividades ofertadas nesses outros espaços:

Os grupos é pra início da crise quando tudo é novidade, então todo grupo é interes-
sante, por mais babacáo assim. Quando a gente vai melhorando assim, parece ser
meio babaca, mas não é. Porque a gente não tá acostumado, mas assim, pintar, essas
coisas, que parece que é pra criança né, mas nossa mente tá como de criança, então
parecia uma coisa meia... às vezes quando passava em mim eu falava: - O que eu tô
fazendo aqui? - mas esses grupos me fizeram enxergar que tinha mais gente igual eu,
que tinha gente numa fase pior que a minha, outras melhores... me ajudou bastante
(M, homem, 28 anos).

Mesmo com a crítica, reconhece a participação grupal como elemento importante para a recuperação durante o processo de crise. Pintar desenhos infantis e promover brincadeiras de crianças eram atividades rotineiras neste serviço, utilizadas com o intuito de entreter as pessoas que ali estavam. Tais abordagens questionam a capacidade das pessoas de corresponderem às atividades de maior complexidade, não dialogando com seus cotidianos e não promovendo participação social para além do lugar de incapacitado e infantilizado.

Vale ressaltar que, mesmo a partir dessa configuração, o CAPS adquire um papel importante no acompanhamento desses jovens, com destaque para o período de crise mais aguda, sendo colocado pelos entrevistados como um local seguro e de confiança para uma escuta e orientação.

\section{Considerações finais}

A experiência destes jovens traz ao debate algumas particularidades do sofrimento psíquico desta população. Ressaltamos o comprometimento da sociabilidade, o afastamento das amizades, o acompanhamento no CAPS e as problemáticas referentes ao uso das medicações. O consumo de bebidas alcoólicas e de outras drogas são questóes importantes para o cuidado em saúde mental e que permeiam aspectos importantes de sociabilização para muitos jovens. É necessário que 
os CAPS ofereçam espaços que estejam estrategicamente alinhados com os enfrentamentos cotidianos destes jovens na busca de uma autonomia possível.

A concepção de sofrimento psíquico por doença demonstrou ser um forte reflexo de como as instituiçóes de cuidado abordam tal questão logo nas primeiras vezes em que elas se manifestam. $\mathrm{O}$ isolamento social é uma das características mais fortes e presentes durante todo o processo da crise.

Apesar do sofrimento vivido, estes jovens criaram algumas estratégias de enfrentamento de sua condiçáo, como o uso de medicamento, que dialoga com o consumo de álcool e outras drogas, um cotidiano mais caseiro, as idas e vindas com amigos, as limitações da crise com a necessidade de trabalhar, conseguindo manter um perfil próximo da juventude do mesmo contexto sociocultural em que estáo inseridos.

O CAPS se mostrou um espaço de acolhimento e confiança para este grupo, especialmente nos momentos de crise, porém traz a discussão de que estratégias se utilizam para compor esse cuidado e do quão alinhadas estão com as políticas públicas de saúde mental. É importante pensar políticas públicas voltadas para as especificidades e demandas da população jovem em sofrimento psíquico severo, uma vez que esta vem fugindo aos olhos nos CAPS Infantis e Adultos.

A crise psíquica revela uma reconfiguração de suas identidades. A construção de suas redes e o saciamento de suas necessidades de pertencimento náo parecem possíveis durante esse período de ruptura, porém motraram indivíduos que se mantêm em movimento na composição contínua de novos territórios (GUATTARI; ROLNIK, 1996), tendo a crise como principal agente de mudanças e criações. ${ }^{8}$

\section{Agradecimentos}

As autoras agradecem a disponibilidade dos jovens participantes da pesquisa em contar suas ricas experiências de vida, ao CNPq eà FAPESP, pelo apoio financeiro. Projeto financiado pela FAPESP (2014/22727-2), sob responsabilidade de Denise Martin.

\section{Referências}

ADADE, M.; MONTEIRO, S. Educação sobre drogas: uma proposta orientada pela redução de danos. Educ. Pesqui. São Paulo, v. 40, n. 1, p. 215-230, mar. 2014. Disponível em: $<$ http://www.scielo.br/scielo.php?script=sci_arttext\&pid=S1517-97022014000100014\&lng $=$ en\&nrm=iso>. Acesso em: 11 mar. 2017. 
ALVES, M.F.P. Juventude, igreja e "mundo" na perspectiva de jovens pentecostais (assembleianos) de Recife. In: Juventude Comtemporânea: culturas, gostos e carreiras. Rio de Janeiro: 7Letras, 2010.

AMARANTE, P. D. C.; RANGEL, M. A liberdade é terapêutica: reinventando vidas na Reforma Psiquiátrica. Revista Eletrônica de Comunicação, Informação \& Inovação em Saúde, v. 3, n. 4, p. 10-16, 2009.

BASAGLIA, F. As instituiçôes da violência. In: AMARANTE, P. (Org.). Escritos selecionados em saúde mental e reforma psiquiátrica. Rio de Janeiro: Garamond, 2010.

BECHELLI, L. P. C. Antipsicóticos de ação prolongada no tratamento de manutenção da esquizofrenia. Parte I. Fundamentos do seu desenvolvimento, benefícios e nível de aceitação em diferentes países e culturas. Rev Latino-am Enfermagem, v. 11, n. 3, p. 341-9, maio/jun. 2003.

BISPO, R. Heterotopias emo: notas etnogáficas sobre desvios e inversôes da juventude emocore no Rio de Janeiro. In: Juventude Contemporânea: culturas, gostos e carreiras. Rio de Janeiro: 7Letras, 2010.

BLIKSTEIN, F. Destino de crianças: estudo sobre internaçôes de crianças e adolescentes em Hospital Público Psiquiátrico. 2012. 91 f. Dissertação (Mestrado em Psicologia Social) Pontifícia Universidade Católica de São Paulo, São Paulo, 2012.

BRASIL. Ministério da Saúde. Lei 10.216, de 06 de abril de 2001. Dispóe sobre a proteção e os direitos das pessoas portadoras de transtornos mentais e redireciona o modelo assistencial em saúde mental. Disponível em: <http://www.planalto.gov.br/ccivil_03/leis/leis_2001/ 110216.htm>.

Ministério da Saúde. Secretaria de Atenção à Saúde. Departamento de Açóes Programáticas Estratégicas. Saúde mental no SUS: os centros de atenção psicossocial. Brasília, 2004. Disponível em: <http://www.ccs.saude.gov.br/saude_mental/pdf/sm_sus. pdf>. Acesso em: 9 out. 2015.

. Ministério da Saúde. Secretaria de Atenção à Saúde. Coordenação Geral de Saúde Mental. Reforma psiquiátrica e política de saúde mental no Brasil. Documento apresentado à Conferência Regional de Reforma dos Serviços de Saúde Mental: 15 anos depois de Caracas. Brasília: OPAS, nov. de 2005.

- Ministério da Saúde. Secretaria de Atenção à Saúde. Núcleo Técnico da Política Nacional de Humanização. Acolhimento nas práticas de produção de saúde. 2. ed. Brasília: Editora do Ministério da Saúde, 2010.

- Ministério da Saúde. Secretaria de Atenção à Saúde. Núcleo Técnico da Política Nacional de Humanização. Clínica ampliada, equipe de referência e projeto terapêutico singular. 2. ed. Brasília, 2008. 

Ministério da Saúde. Portaria No 336, de 19 de fevereiro de 2002. Disponível em: <http://bvsms.saude.gov.br/bvs/saudelegis/gm/2002/prt0336_19_02_2002.html>. Acesso em: 11 mar. 2017.

. Ministério da Saúde. Portaria GM n 224/1992. Disponível em: <http://www. saude.sc.gov.br/geral/planos/programas_e_projetos/saude_mental/portaria_n224.htm>. Acesso em: 11 mar. 2017.

. Ministério da Saúde. Portaria $n^{\circ}$ 3.088, de 23 de dezembro de 2011. Disponível em: <http://bvsms.saude.gov.br/bvs/saudelegis/gm/2011/prt3088_23_12_2011_rep.html>. Acesso em: 11 mar. 2017.

. Ministério do Planejamento, Orçamento e Gestão. Instituto Brasileiro de Geografia e Estatística. Pesquisa Nacional por Amostra de Domicílios: síntese de indicadores, 2013. Disponivel em: <http://biblioteca.ibge.gov.br/visualizacao/livros/liv94414.pdf>.

COSTA, I. I. Adolescência e a primeira crise psicótica: problematizando a continuidade entre o sofrimento psíquico normal e o psíquico grave. Anais do II Congresso Internacional de Psicopatologia Fundamental, set. 2006. Disponível em: <http://www. fundamentalpsychopathology.org/anais2006/4.69.3.1.htm>. Acesso em: 10 mar. 2017.

CUNHA, C. C.; BOARINI, L. M. O Lugar da Criança e do Adolescente na Reforma Psiquiátrica. Revista Psicologia e Saúde, [S.1.], jul. 2011. ISSN 2177-093X. Disponível em: <http://www.gpec.ucdb.br/pssa/index.php/pssa/article/view/83>. Acesso em: 11 mar. 2017.

DAYRELL, J. O rap e o funk na socialização da juventude. Educação e Pesquisa, São Paulo, v. 28, n. 1, p. 117-136, jan./jun. 2002.

DELL'ACQUA, G.; MEZZINA, R. Resposta à crise. In: DELGADO, J. A loucura na sala de jantar. São Paulo: Ed. Autor, 1991, p. 225-232.

FIOCRUZ. Uso Racional de Psicofármacos, a. 1, v. 1, abr./jun. 2006. Disponível em: <http:// www.ensp.fiocruz.br/portal-ensp/judicializacao/pdfs/289.pdf>. Acesso em: 9 fev. 2016.

GRANJA, E. et al. O (não) lugar do homem jovem nas políticas de saúde sobre drogas no Brasil: aproximaçóes genealógicas. Ciênc. saúde coletiva. Rio de Janeiro, v. 20, n. 11, p. 3.447-3.455, nov. 2015 . Disponível em: <http://www.scielo.br/scielo.php?script=sci_ arttext\&pid=S1413-81232015001103447\&lng=en\&nrm=iso >. Acesso em: 11 mar. 2017.

GUATTARI, F.; ROLNIK, S. Micropolitica: cartografias do desejo. Petrópolis: Vozes, 1996.

INSTITUTO BRASILEIRO DE GEOGRAFIA E ESTATÍSTICA. Censo Demográfico. São Paulo: IBGE, 2000.

LOURENÇO, A. L. C. Otakus: jovens brasileiros e cultura pop nipônica (2009). In: Juventude Contemporânea: culturas, gostos e carreiras. Rio de Janeiro: 7Letras, 2010.

LOUZÃ, M.R. Manejo clínico do primeiro episódio psicótico. Rev. Bras. Psiquiatr., 22(1):45, 2000. 
MACHADO, G. M. C. Praça Roosevelt: sociabilidade e conflitos em um pedaço skatista da cidade de São Paulo. Revista Perifèria, n. 19, p. 82-107, jun. 2014.

MAGNANI, J. G. A antropologia urbana e os desafios da metrópole. Tempo soc. São Paulo, v. 15, n. 1, p. 81-95, abr. 2003. Disponível em: <http://www.scielo.br/scielo.php?script=sci_ arttext\&pid=S0103-20702003000100005\&lng=pt\&nrm=iso >. Acesso em: 16 mar. 2016.

. De perto e de dentro: notas para uma etnografía urbana. Rev. Bras. de Ciências Sociais, 17(49), jun. 2002.

MANGiA, E. F. et al. Necessidades de Adolescentes com Sofrimento Psíquico. Rev. Ter. Ocup. Univ. São Paulo, 14(3):123-32, set./dez. 2003.

MARGULIS, M.; URRESTI, M. La juventud es más que una palabra. In: MARGULIS, M. (Org.). La juventud es más que una palabra. Buenos Aires: Biblos,1996.

MARTIN, D.; QUIRINO, J.; MARI, J. Depressão entre mulheres da periferia de São Paulo. Rev. Saúde Pública. São Paulo, v. 41, n. 4, p. 591-597, Ago. 2007. Disponível em: $<$ http://www.scielo.br/scielo.php?script=sci_arttext\&pid=S0034-89102007000400013\&ln $\mathrm{g}=\mathrm{en} \& \mathrm{nrm}=\mathrm{iso}>$. Acesso em: 2 nov. 2016.

ORGANIZAÇÃO MUNDIAL DA SAÚDE. Promoción del uso racional de medicamentos: componentes centrales. Perspectivas políticas sobre medicamentos de la OMS. Ginebra (SUI), 2002.

PAIS, J. M. A construção sociológica da juventude: alguns contributos. Análise Social. Lisboa, v. 25, n. 105/106, 1990.

SÃO PAULO. Cidade Tiradentes: O bairro que mais parece uma cidade. Subprefeitura de Cidade Tiradentes. 2014. Disponível em: <http://www.prefeitura.sp.gov.br/cidade/secretarias/ subprefeituras/cidade_tiradentes/historico/index.php?p=94>. Acesso em: 28 set. 2016.

- Secretaria da Saúde do Município (SMS/SP); Instituto Via Pública. Atlas da Saúde da Cidade de São Paulo, 2011.

SOARES, C. B. et al. Juventude e consumo de drogas: oficinas de instrumentalização de trabalhadores de instituiçóes sociais, na perspectiva da saúde coletiva. Interface. Botucatu , v. 13, n. 28, p. 189-199, mar. 2009. Disponível em: <http://www.scielo.br/scielo. php?script=sci_arttext $\&$ pid $=S 1414-32832009000100016 \& \operatorname{lng}=$ en $\& n r m=i s o>$. Acesso em: 11 mar. 2017.

SOARES, R. et al . Medidas judiciais atinentes à atenção em saúde mental de adolescentes em conflito com a lei. Interface. Botucatu, v. 21, n. 60, p. 123-131, mar. 2017 . Disponível em: <http://www.scielo.br/scielo.php?script=sci_arttext\&pid=S1414-32832017000100123\&lng $=$ en\&nrm=iso>. Acesso em: 11 mar. 2017.

SPAGGIARE, E. Família joga bola: constituição de jovens futebolistas na várzea paulistana. 2015. Tese (Doutorado em Antropologia Social) - Universidade de São Paulo, São Paulo, 2015. 
TAÑO, B. L.; MATSUKURA, T. S. Saúde mental infanto-juvenil e desafios do campo: reflexôes a partir do percurso histórico. Cad. Ter. Ocup. UFSCar. São Carlos, v. 23, n. 2, p. 439-447, 2015. Disponível em: <http://www.cadernosdeterapiaocupacional.ufscar.br/index. php/cadernos/article/view/865>. Acesso em: 11 mar. 2017.

XAVIER, M. S. et al. O significado da utilização de psicofármacos para indivíduos com transtorno mental em acompanhamento ambulatorial. Esc. Anna Nery. Rio de Janeiro, v. 18, n. 2, p. 323-329, jun. 2014. Disponível em: <http://www.scielo.br/scielo.php?script=sci_ arttext\&pid=S1414-81452014000200323\&lng=en\&nrm=iso>. Acesso em: 9 fev. 2017.

\section{Notas}

${ }^{1}$ Os CAPS são serviços de saúde abertos e comunitários do Sistema Único de Saúde (SUS). Eles são um lugar de referência e tratamento para pessoas que sofrem com transtornos mentais, psicoses, neuroses graves e demais quadros, cuja severidade e/ou persistência justifiquem sua permanência num dispositivo de cuidado intensivo, comunitário, personalizado e promotor de vida, criado para ser substitutivo às internaçôes em hospitais psiquiátricos (BRASIL, 2002).

${ }^{2}$ Projeto do Governo do Estado de São Paulo voltado à educação e formação nas mais variadas formas de expressão artística.

${ }^{3}$ Projeto de pesquisa aprovado pelo Comitê de Ética em Pesquisa da UNIFESP, sob o parecer n. 936.150 .

${ }^{4}$ Ver Bispo (2010); Dayrell (2002); Spaggiare (2015), Lourenço (2010); Machado (2014) e Alves (2010).

${ }^{5}$ Caracterizado pela escuta qualificada oferecida pelos trabalhadores às necessidades do usuário de modo a garantir o acesso oportuno desses usuários a tecnologias adequadas às suas necessidades, ampliando a efetividade das práticas de saúde (BRASIL, 2010).

${ }^{6} \mathrm{O}$ Projeto Terapêutico Singular se define como um conjunto de propostas de condutas terapêuticas articuladas, para um sujeito individual ou coletivo, resultado da discussão coletiva de uma equipe interdisciplina (BRASIL, 2008).

${ }^{7}$ Drogas usadas no tratamento dos transtornos psicóticos (OMS, 2002).

${ }^{8}$ A. E. Milhomens participou da concepção e realização da pesquisa, análise e interpretação dos dados e redação do artigo. D. Martin participou da concepção da pesquisa, orientou, realizou a revisão crítica do conteúdo intelectual do artigo e aprovou a versão a ser publicada. Este artigo é inédito, resultado da pesquisa de mestrado de Aline Ernandes Milhomens, Rupturas e transformaçôes na vida de jovens acompanhados em um CAPS Adulto na cidade de São Paulo. Aprovada pelo Comitê de Ética em Pesquisa da UNIFESP, parecer n. 936.150, sob orientação de Denise Martin. 


\section{Abstract}

Ruptures and transformations in the lives of young people accompanied in an adult CAPS

This article aims to approach the ruptures and transformations caused in the life of young people who have undergone the experience of psychic suffering accompanied in an Adult Psychosocial Care Center (CAPS) in the city of São Paulo. This research was carried out through an ethnography in the accompaniment of a group of young people from the service. Participant observation techniques, records in a field book and individual interviews were used. We observed compromise of sociability, withdrawal from friendships, limitations with the use of medication and difficulty in obtaining a formal job. The consumption of alcohol and other drugs emerged as a matter for care, since it permeates important aspects of socialization. The conception of psychic suffering based on the idea of illness is a reflection of how CAPS and other health services approach the theme. The CAPS has shown itself to be a welcoming and trusting space, especially in times of crisis, but it raises the discussion about what strategies it uses to compose such care to this specific population and how aligned they are with mental health policies.

> Keywords: young adult; psychic suffering; social participation; mental health services. 